Pacific Journal of Mathematics

A NOTE ON LEFT MULTIPLICATION OF SEMIGROUP 


\title{
A NOTE ON LEFT MULTIPLICATION OF SEMIGROUP GENERATORS
}

KARL GuSTAFSON

\begin{abstract}
It is shown in this note that if $A$ is the infinitesimal generator of a strongly continuous semigroup of contraction operators in any Banach space $X$, then so is $B A$ for a broad class of bounded operators $B$; the only requirement on $B$ is that it transforms "in the right direction".
\end{abstract}

In the recent paper [1] the following interesting result was obtained.

THEOREM 1 (Dorroh). Let $X$ be the Banach space of bounded functions on a set $S$ under the supremum norm, let $A$ be the infinitesimal generator of a contraction semigroup in $X$, and let $B$ be the operator given by multiplication by $p, p X \subseteq X$, where $p$ is a positive function defined on $S$, bounded above, and bounded below above zero. Then $B A$ is also the infinitesimal generator of a contraction semigroup in $X$.

This leads naturally to the general question of preservation of the generator property under left multiplication; the purpose of this note is to present Theorem 2 below, which shows that for any Banach space, a large class of operators $B$ are acceptable. In the following, the word "generator" will always mean generator of contraction semigroup.

In this note we will consider only left multiplication by everywhere defined bounded operators $B$. It is easily seen (e.g., [2, Corollary 3]) that $A$ generates a contraction semigroup if and only if $c A$ does, $c>0$. Also by [4, Th. 2.1], if $A$ is bounded, $B A$ is a generator if and only if $B A$ is dissipative; in this case clearly right multiplication also yields a generator. See $[4,5]$ for dissipativeness; we use dissipativeness in the sense [4], and recall that if $B A$ is a generator, then $B A$ is dissipative in all semi-inner products on $X$.

THEOREM 2. Let $X$ be any Banach space, $A$ the infinitesimal generator of a contraction semigroup in $X$, and $B$ a bounded operator in $X$ such that $\|\varepsilon B-I\|<1$ for some $\varepsilon>0$. Then $B A$ generates a contraction semigroup in $X$ if and only if $B A$ is dissipative, (i.e., $\operatorname{Re}[B A x, x] \leqq 0$, all $x \in D(A),[u, v]$ a semi-inner product (see [4])). 
Proof. We note that $R(B)=X$ when $\|\varepsilon B-I\|<1$ for some $\varepsilon>0$; to show that $B A$ is a generator it suffices to show that $\varepsilon B A$ is a generator for some positive $\varepsilon$. From the relation $\|\varepsilon B-I\|<$ $1 \leqq\left\|(I-\varepsilon B A)^{-1}\right\|^{-1}$ we have by [2, Lemma 1] that:

$$
\beta(I-\varepsilon B A)=\beta((I-\varepsilon B A)+(\varepsilon B-I)) \equiv \beta(\varepsilon B(I-A))=\beta(\varepsilon B)=0,
$$

where $\beta(T)=\operatorname{dim} X / \mathrm{Cl}(R(T))$ is the deficiency index of an operator $T$. A closed implies $\varepsilon B A$ closed (and therefore $I-\varepsilon B A$ closed), since $\varepsilon B A=A+(\varepsilon B-I) A$ and $\|\varepsilon B-I\|<1 ; B A$ dissipative implies that $I-\varepsilon B A$ possesses a continuous inverse, so that we therefore have $R(I-\varepsilon B A)$ closed, and thus $B A$ the generator of a contraction semigroup. This result also follows quickly from [2, Theorem 2].

In the above we made use of basic index theory as may be found in [3] and the well-known characterizations of generators as may be found in [3, 4, 5], for example. The index theory notation here is a convenience only; the arguement can be presented without it.

\section{COROLlaRY 3. Theorem 1 stated above.}

Proof. As shown in [1], $p A$ is dissipative with respect to the semi-inner product used there, and clearly $0<m \leqq p(s) \leqq M$ implies that $|\varepsilon p-1|<1-\varepsilon m$ for small enough $\varepsilon$.

Corollary 4. Let $B$ be of the form $c I+C,\|C\|<c, C A$ dissipative. Then $B A$ is a generator if $A$ is.

Proof. Clearly $c^{-1} B$ satisfies the conditions of Theorem 2; note $\|\varepsilon B-I\|<1$ for some $\varepsilon>0$ if and only if $B$ is of the form $c I+C$, $\|C\|<c$.

Remarks. The condition $B A$ dissipative in Theorem 2, necessary for $B A$ to be a generator, requires (in general) that $B$ be in a "positive" rather than a dissipative direction. For example, if $A, B$, and $B A$ are self-adjoint operators on a Hilbert space, then $A$ is a generator if and only if $A$ is negative, and then $B A$ is a generator if $B$ is positive.

The condition $\|\varepsilon B-I\|<1$ in Theorem 2 is easily seen to be equivalent to the condition: $B$ strongly accretive, i.e., $\exists m=m(B)$ such that $\operatorname{Re}[B x, x] \geqq m>0$ for $\|x\|=1$, where $[u, v]$ is the semiinner product being used (see [4]). It is a sharp condition since equality $\|\varepsilon B-I\|=1$ cannot be permitted in general, as seen from the example $B=0, A$ unbounded, for then $B A$ is not closed.

The effect of Theorem 2 is that, after the application of index 
theory therein, one sees that the essential question concerning when $B A$ is a generator is the question of when $B A$ is dissipative. Three situations which can then occur are: (i) as in [1], for special operators $B$, one can find a semi-inner product for which $B A$ is dissipative; (ii) A commutes with $B$ (see [3]), for which one can easily obtain results such as $A$ self-adjoint, dissipative, and $B$ accretive imply $B A$ dissipative; (iii) general (noncommuting) $A$ and $B$. For case (iii) one can obtain the following interesting result (proof given in forthcoming paper by the author, Math. Zeitschrift). Let $-A$ and $B$ be strongly accretive operators on a Banach space. If

$$
\min _{\varepsilon}\|\varepsilon B-I\| \leqq m(-A) \cdot\|A\|^{-1},
$$

then $B A$ is dissipative. In particular, let $A$ and $B$ be self-adjoint operator: then $(\|B\|-m(B)) \cdot(\|B\|+m(B))^{-1} \leqq m(-A) \cdot\|A\|^{-1}$ is sufficient. Moreover these conditions can be sharpened by introducing the concept of the cosine of an operator. For certain operators the condition for $B A$ to be dissipative can then be written as $\sin B \leqq \cos A$.

The author appreciates useful expository suggestions from the referee. Extensions of these results to unbounded right and left multiplication will appear in a forthcoming paper by the author and G. Lumer.

\section{REFERENCES}

1. J. R. Dorroh, Contraction semigroups in a function space, Pacific J. Math. 19, (1966), 35-38.

2. K. Gustafson, A perturbation lemma, Bull. Amer. Math. Soc. 72 (1966), 334-338.

3. T. Kato, Perturbation Theory for Linear Operators, Springer-Verlag, 1966.

4. G. Lumer and R. S. Phillips, Dissipative operators in a Banach space, Pacific J. Math. 11 (1961), 679-698.

5. E. Nelson, Feynman integrals and the Schrödinger equation, J. Mathematical Phys. 5 (1964), 332-343.

Received April 3, 1967, and in revised form July 11, 1967. This work was partially supported by N.S.F. G.P. $7041 \mathrm{X}$.

UNIVERSITY OF MINNESOTA

AND

Institut Battelle, Geneva 



\section{PACIFIC JOURNAL OF MATHEMATICS}

\section{EDITORS}

\author{
H. ROYDEN \\ Stanford University \\ Stanford, California
}

\author{
J. P. JANS \\ University of Washington \\ Seattle, Washington 98105
}

J. DugundJI

Department of Mathematics

Rice University

Houston, Texas 77001

RICHARD ARENS

University of California

Los Angeles, California 90024

\section{ASSOCIATE EDITORS}
E. F. BECKENBACH
B. H. NeumanN
F. WOLF
K. YOSIDA

\section{SUPPORTING INSTITUTIONS}

\author{
UNIVERSITY OF BRITISH COLUMBIA \\ CALIFORNIA INSTITUTE OF TECHNOLOGY \\ UNIVERSITY OF CALIFORNIA \\ MONTANA STATE UNIVERSITY \\ UNIVERSITY OF NEVADA \\ NEW MEXICO STATE UNIVERSITY \\ OREGON STATE UNIVERSITY \\ UNIVERSITY OF OREGON \\ OSAKA UNIVERSITY \\ UNIVERSITY OF SOUTHERN CALIFORNIA
}

\author{
STANFORD UNIVERSITY \\ UNIVERSITY OF TOKYO \\ UNIVERSITY OF UTAH \\ WASHINGTON STATE UNIVERSITY \\ UNIVERSITY OF WASHINGTON \\ AMERICAN MATHEMATICAL SOCIETY \\ CHEVRON RESEARCH CORPORATION \\ TRW SYSTEMS \\ NAVAL ORDNANCE TEST STATION
}

\footnotetext{
Mathematical papers intended for publication in the Pacific Journal of Mathematics should be in typed form or offset-reproduced, double spaced with large margins. Underline Greek letters in red, German in green, and script in blue. The first paragraph or two must be capable of being used separately as a synopsis of the entire paper. It should not contain references to the bibliography. Manuscripts may be sent to any one of the four editors. All other communications to the editors should be addressed to the managing editor, Richard Arens, University of California, Los Angeles, California 90024.

Each author of each article receives 50 reprints free of charge; additional copies may be obtained at cost in multiples of 50 .

The Pacific Journal of Mathematics is published monthly. Effective with Volume 16 the price per volume (3 numbers) is $\$ 8.00$; single issues, $\$ 3.00$. Special price for current issues to individual faculty members of supporting institutions and to individual members of the American Mathematical Society: $\$ 4.00$ per volume; single issues $\$ 1.50$. Back numbers are available.

Subscriptions, orders for back numbers, and changes of address should be sent to Pacific Journal of Mathematics, 103 Highland Boulevard, Berkeley 8, California.

Printed at Kokusai Bunken Insatsusha (International Academic Printing Co., Ltd.), 7-17, Fujimi 2-chome, Chiyoda-ku, Tokyo, Japan.

PUBLISHED BY PACIFIC JOURNAL OF MATHEMATICS, A NON-PROFIT CORPORATION

The Supporting Institutions listed above contribute to the cost of publication of this Journal, but they are not owners of publishers and have no responsibility for its content or policies.
} 


\section{Pacific Journal of Mathematics}

\section{Vol. 24, No. $3 \quad$ July, 1968}

Duane W. Bailey, On symmetry in certain group algebras ............ 413

Lawrence Peter Belluce and Surender Kumar Jain, Prime rings with a one-sided ideal satisfying a polynomial identity ................ 421

L. Carlitz, A note on certain biorthogonal polynomials ............. 425

Charles O. Christenson and Richard Paul Osborne, Pointlike subsets of a manifold ......................................... 431

Russell James Egbert, Products and quotients of probabilistic metric

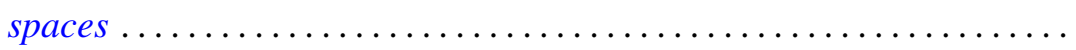

Moses Glasner, Richard Emanuel Katz and Mitsuru Nakai, Bisection into small annuli ..................................... 457

Karl Edwin Gustafson, A note on left multiplication of semigroup

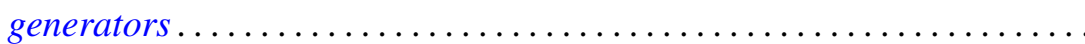

I. Martin (Irving) Isaacs and Donald Steven Passman, A characterization of groups in terms of the degrees of their characters. II ............. 467

Howard Wilson Lambert and Richard Benjamin Sher, Point-like

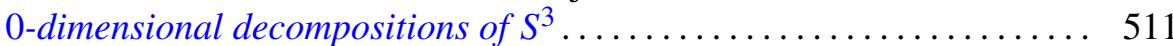

Oscar Tivis Nelson, Subdirect decompositions of lattices of width two ..... 519

Ralph Tyrrell Rockafellar, Integrals which are convex functionals . . . . . . . 525

James McLean Sloss, Reflection laws of systems of second order elliptic differential equations in two independent variables with constant coefficients ...

Bui An Ton, Nonlinear elliptic convolution equations of Wiener-Hopf type in a bounded region

Daniel Eliot Wulbert, Some complemented function spaces in $C(X)$

Zvi Ziegler, On the characterization of measures of the cone dual to a generalized convexity cone. 